\title{
Secondary Infection of Buruli Ulcer Lesions
}

\author{
Grace Semabia Kpeli and Dorothy Yeboah-Manu
}

\section{$1 \quad$ Background}

Proper wound care is increasingly becoming a very crucial component of the management of Buruli ulcer (BU). The cytopathic activity of the main virulent factor of the causative pathogen, $M$. ulcerans, leads to the formation of extensive necrotic ulcerative lesions, which are a good medium for the growth of other bacteria. Data from a number of clinical studies showed that in up to $80 \%$ of cases presenting with limited (category I and II) lesions, healing occurs within 6 month after onset of antibiotic treatment without the need for surgery [1-7]. However, wound healing is delayed in a proportion of affected patients, in particular in those reporting with large lesions $[4,8,9]$. In particular, after completion of antimycobacterial therapy good monitoring and wound care is important to avoid massive secondary bacterial infections [10], potentially affecting the healing potential of wounds and increasing the risk of more severe pathology and sepsis. The WHO recommends that secondary infection in BU should be suspected when a wound develops cellulitis or becomes painful [11]. Secondary infection in BU disease is not well characterized and recognized because it is assumed to be infrequent [11]. Thus, its occurrence has been documented only by few studies [10, 12-16]. Previously, it was speculated that mycolactone secreted by $M$. ulcerans during active disease may sterilize BU wounds and prevent secondary infection by other bacteria, since a number of macrolides have broad spectrum activity against many bacterial species including streptococci, pneumococci, staphylococci, enterococci, mycoplasma, mycobacteria, rickettsia, and chlamydia [17]. However, several studies [10, 14] have proven

\author{
G. S. Kpeli \\ University of Health and Allied Sciences, Ho, Ghana \\ D. Yeboah-Manu $(\bowtie)$ \\ Noguchi Memorial Institute for Medical Research, Accra, Ghana \\ University of Ghana, Accra, Ghana \\ e-mail: dyeboah-manu@noguchi.ug.edu.gh \\ (C) The Author(s) 2019 \\ G. Pluschke, K. Röltgen (eds.), Buruli Ulcer, \\ https://doi.org/10.1007/978-3-030-11114-4_13
}


that mycolactone does not prevent secondary bacterial infection of BU lesions. In these studies, the microbial flora of BU wounds was found to be very diverse and a broad range of bacteria species colonizing the lesions were identified. Furthermore, research by Scherr [18] using synthetic mycolactones also demonstrated the growth of the bacterial species Streptococcus pneumoniae, Neisseria meningitidis and Escherichia coli, as well as the yeast Saccharomyces cerevisae and the amoeba Dictyostelium discoideum in the presence of mycolactone. Thus, secondary infection in BU may be more common than formerly thought.

\section{Bacterial Species Associated with Secondary Infections}

\subsection{Species Diversity}

Extensive work on the microbial flora of BU wounds has been done by research groups in Ghana [10], Benin [14] and Nigeria [13]. Yeboah-Manu and Barogui studied the microbial flora of BU patients before, during and post antibiotic treatment while the study by Anyim included pre-treatment patients only. In the study by Yeboah-Manu et al., many different bacterial species were isolated, including Staphylococcus aureus, Pseudomonas aeruginosa, Proteus mirabilis, Coagulase negative Staphylococcus, Chryseomonas luteola, Enterobacter cloacae, Klebsiella pneumonia, Escherichia coli, Streptococcus dysgalactia, Providencia stuartii, Staphylococcus haemolyticus, Morganella morganii, Streptococcus agalactia, Staphylococcus warneri, Proteus vulgaris and other Gram negative bacteria. $S$. aureus, $P$. aeruginosa and $P$. mirabilis were frequently isolated pre-treatment. During treatment, $P$. aeruginosa and $P$. mirabilis were the dominating isolates, while $P$. aeruginosa, $P$. mirabilis and $S$. aureus were the most frequently isolated bacteria post antibiotic treatment. The study by Barogui isolated Group A streptococci, Group B or C streptococci, S. aureus, S. epidermidis, Staphylococcus sp., $P$. aeruginosa and Enterobacteriaceae with $S$. aureus and $P$. aeruginosa dominating pre and post treatment and $P$. aeruginosa being the most frequently isolated bacteria during treatment. The study by Anyim et al. isolated $S$. aureus, A. hydrophila P. aeruginosa, K. pneumoniae, Enterobacter cloacae, Pseudomonas pseudomallei and Burkholderia cepacia.

The species diversity isolated from the wounds represent the spectrum of microbial isolates commonly isolated from other wound types such as burn and infected diabetic foot ulcers. However, the main bacteria commonly cited as responsible for wound infection and healing delay are $S$. aureus, $P$. aeruginosa and $\beta$-hemolytic streptococci [19-21].

$S$. aureus and $P$. aeruginosa dominating among the isolates detected in the BU lesions, have been found to be associated with infection and healing delay in both chronic and acute wounds and are frequently implicated in healthcare-associated infections. The virulence of these bacterial species is based on their ability to produce a number of destructive enzymes and toxins. Through intrinsic and acquired mechanisms, they exhibit increased resistance to many antimicrobials. They also 
have the ability to form biofilms which increase their persistence and antibiotic tolerance [21-23]. Interestingly, in the two studies which assessed the species diversity at different time points [10, 14], S. aureus was not isolated from patient lesions during antibiotic treatment. Further research will be needed to explain the absence of this bacterial species during treatment and its probable "re-emergence" post treatment.

\section{Bacterial Burden}

The role of microorganisms in wound healing and infection is diverse and related not only to the type of microbial species colonizing a wound but also to the number of microorganisms or the wound's bioburden. Localized wound infection is a significant cause of impaired healing and wound chronicity [24]. The pathogenic effects of bacteria may be increased through the formation of biofilms and the release of toxic products [22]. Endotoxins released by Gram-negative bacteria in wounds lead to elevated levels of proinflammatory cytokines (IL-1 and tumour necrosis factor). In addition, factors including the release of free radicals, degradation of growth factors, production of metabolic products, consumption of local oxygen and interference with collagen formation may also result in a non-conducive wound environment. The effects of these mechanisms increase with high bacterial loads leading to impaired wound healing $[20,21]$.

Many studies have confirmed that, a wound's bioburden is an important predictor of wound infection and wound healing. In decubitus ulcers, wound healing was found to progress only when the microbial load of wound fluid was below $10^{6}$ colony forming units (cfu) per $\mathrm{ml}$ of wound exudates $(\mathrm{cfu} / \mathrm{ml})$ or per gram of tissue (cfu/g) [25] with healing being inhibited above this value. The success of skin grafts has also been demonstrated to be associated with bacterial loads $<5 \times 10^{4} \mathrm{cfu} / \mathrm{cm}^{2}$ [26]. These studies and others on diabetic foot ulcers and pressure ulcers led to the conclusion that the determination of bacterial loads could be useful in the prediction of wound healing and infection [27-32]. Thus traditionally, bacterial levels above $10^{6} \mathrm{cfu} / \mathrm{ml}$ are used as predictors of wound infection and related wound healing delay. An exception to this is, where a wound is colonized by $\beta$-haemolytic streptococci, which has been found to cause disease even at levels $<10^{5} \mathrm{cfu} / \mathrm{g}$ of tissue.

A recent study [33] assessing the bacterial load in the lesions of BU patients longitudinally to gain insight into the evolution of the bacterial load showed that levels of bacteria are not constant throughout the period of antibiotic treatment of BU patients. High bacterial loads were reported before and after treatment compared to decreased loads during treatment. A study by Gardner [34] reported a decrease in bacterial load in subjects on systemic antibiotics compared to those not on antibiotics. This could account for the decreased loads reported in BU patients during treatment with the 8-week regimen of streptomycin and rifampicin (SR8), which have broad spectrum activity. This result was also in agreement with clinical signs observed during the treatment period such as fewer lesions presenting with slough, necrosis and high wound exudate production. The increase in bacterial burden in 
the BU lesions was found to be highest after the antibiotic treatment phase. The impact of an increased bacterial load on wound healing cannot be underestimated and the presence of bacteria in wounds even in the absence of obvious clinical signs can inhibit the normal wound healing process. BU wound management guidelines should therefore consider and include strategies for preventing secondary infection.

\section{$4 \quad$ Diagnosing Secondary Infection in BU}

Generally, for a wound to be considered as infected, bacterial multiplication should increase strong enough to induce immune reactions from the host. Clinically, such reactions will present with signs and symptoms such as pain, swelling, erythema (redness), increased temperature, malodour and discoloured granulation tissue etc. Diagnosing wound infection is challenging and ideally, a holistic analysis of lesions employing all available diagnostic methods is favourable [21].

Diagnosis should consider both the clinical presentation of the wound and the results of microbiological investigations through quantitative and qualitative investigations involving direct microscopy and cultures. In diagnosing BU secondary infection, where possible, histopathological analysis of suspected secondarily infected lesions gives an added advantage to the quality of results obtained. In the absence of specimen for histopathological analysis, bacterial loads above $10^{5} \mathrm{cfu} / \mathrm{g}$ or $\mathrm{cfu} / \mathrm{ml}$ are the accepted gold standard in diagnosing localized infection [32, 35, 36] as research has shown that the bacterial burden of a wound has an inverse relationship with wound healing and wound healing is likely to progress only when bacterial counts are below $10^{6} \mathrm{cfu} / \mathrm{ml}[25,27-32]$.

Yeboah-Manu [10] combined clinical observations, histopathological analysis, qualitative and quantitative microbiological methods to identify secondary infection in BU wounds. Results revealed correlations between clinical signs and microbiological and histopathological features (Fig. 1). Lesions of 28 patients with clinical indications of infection after SR8 treatment were analyzed and $75 \%$ of these lesions yielded quantitative cfu counts $>10^{6} \mathrm{cfu} / \mathrm{ml}$ with an average value of $1.2 \times 10^{9} \mathrm{cfu} /$ $\mathrm{ml}$, clearly above the levels representing the lower limits of infection by quantitative microbiology $\left(10^{5} \mathrm{cfu} / \mathrm{g}\right.$ or $\left.\mathrm{cfu} / \mathrm{ml}\right)$. Among these patients, clinical signs highly predictive for infection were pain and yellow discharge. Histopathology also confirmed the presence of infecting bacteria in $75 \%$ of the lesions microbiologically classified as infected.

\section{$5 \quad$ Drug Susceptibility Patterns of Bacterial Isolates from BU Lesions}

Countries with a high burden of infectious diseases rely on antibiotics as an important part of their health-care. There are currently no guidelines for the management of secondarily infected BU lesions; however, it is common practice among health 

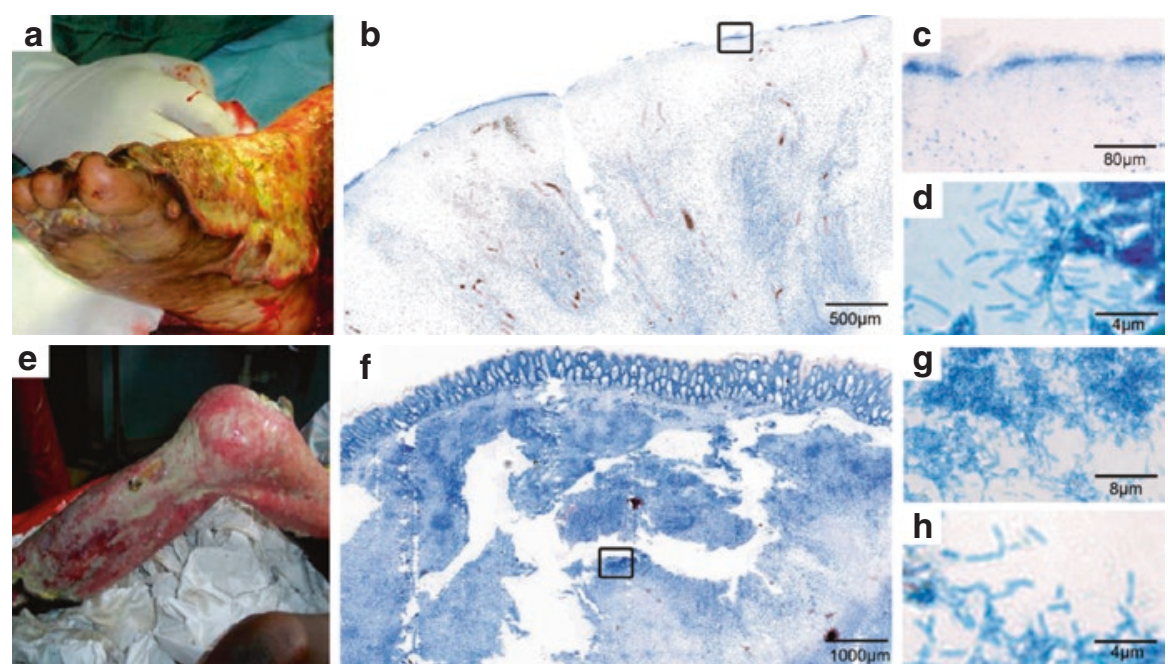

Fig. 1 Histopathological analysis of tissue from two patients excised 6 and 8 weeks respectively after SR8 treatment respectively. Histological sections were stained with Ziehl-Neelsen (acid fast bacteria) and methylene blue (DNA, secondary infection). (a) clinical presentation of a patient presenting with a large lesion on the right foot. (b) overview over excised tissue specimen (open ulcer surface) revealing the presence of an infection (blue band, box). (c/d) higher magnification confirming the presence of densely packed rods. (e) clinical presentation of a patient presenting with a large lesion covering the left leg. (f) overview over excised tissue specimen revealing an epidermal hyperplasia as well as a strong edema. $(\mathbf{g} / \mathbf{h})$ : secondary infection of the dermal and subcutaneous tissue with rod shaped bacteria [10]

personnel to prescribe additional antibiotics for BU patients suspected of having a secondary infection. Studies of the antibiotic susceptibility patterns of bacterial isolates from BU wounds has revealed a high level of resistance to the commonly prescribed first-line drugs against infectious diseases including the BU treatment drugs streptomycin and rifampicin [10, 14, 37].

The high level of streptomycin resistance reported in Ghana is not surprising as it is a widely used antibiotic in animal husbandry for treatment and disease prevention. It was also until recently used as a first line treatment drug for tuberculosis in Ghana. Thus years of streptomycin use in both humans and animals appears to have resulted in selection pressure leading to high resistance rates. Lower levels of resistance were reported for amikacin, gentamicin and tobramycin (also aminoglycosides) as well as for the carbapenem imipenem [10]. Amikacin, gentamicin and tobramycin are expensive injectable drugs only prescribed for serious and life-threatening infections. These factors discourage the abuse of these antibiotics and contribute to the low resistance levels reported. Carbapenems are the last choice of antibiotics used in treatment of infections due to extended spectrum $\beta$-lactamase (ESBL)-producing bacteria and are not widely used or easily accessible. Meropenem is the only carbapenem approved for use in Ghana and has so far not recorded any resistance though it has been on the market since 2002 . 
Drug resistant bacteria including multi-drug resistant (MDR) P. aeruginosa, Methicillin resistant $S$. aureus (MRSA) and Extended Spectrum $\beta$-lactamase producers were also detected in BU lesions [10, 14, 37-39]. Of increased concern is the high frequency of MRSA with prevalence rates of 33\%, 38\%, $13 \%$ and $22.8 \%$ reported $[10,14,37,38]$.

The resistome of whole genome sequenced $S$. aureus isolates from BU patients was investigated by Kpeli [37] and Amissah [12]. Kpeli's study identified antibiotic resistance genes coding for resistance to $\beta$-lactams (blaZ), chloramphenicol (cat and catpC221), trimethoprim $(d f r G)$, methicillin (mecA), quinolone (norA), streptomycin (str) and tetracycline (tetK, tet $L$ and tet $M)$. The study also further investigated the $r p o B$ gene of rifampicin resistant strains and identified two known amino acid substitutions H481N and I527M implicated in rifampicin resistance. Amissah's study identified resistance to penicillin characterized by the presence of various blaZ operons; resistance to chloramphenicol (catA and fexB), tetracycline (tetK, tet $L$ and $t e t M)$, trimethoprim ( $d r f G)$, streptomycin ( $s t r)$, and rifampicin ( $r p o B$ mutation encoding an amino acid substitution that changed Asp471 into Gly). Six methicillin resistant isolates were also identified with five encoding the mecA gene and one identified as a borderline oxacillin resistant strain.

Based on the results from various studies on the antimicrobial susceptibilities of bacteria isolated from BU wounds, it is clear that the use of antibiotics needs to be minimized. The definition of secondary infection is subjective in many cases and clinicians are unsure of how to manage wounds, especially if they show no clinical evidence of infection. Specific guidelines on the management of BU wounds secondarily infected by other bacterial species are urgently needed [14]. Guidelines on whether to use antibiotics for treating these wounds, the choice of antimicrobial agents to prescribe, the duration of treatment and whether topical antimicrobials should be prescribed and prioritized over systemic antimicrobials need to be clarified.

\section{$6 \quad$ Molecular Epidemiology}

\subsection{Sources of Infection}

All wounds healing by secondary intention are prone to microbial contamination. Wounds can be infected from the environment, surrounding skin and also from endogenous sources such as the nasal mucosa, gastrointestinal tract and the genitourinary tract. Sources of wound contamination in the health-center can be from health-care workers (HCW), other patients and the inanimate environment. Most of the bacterial pathogens recovered from the lesions of BU patients are known nosocomial pathogens. A study by Kpeli et al. [37] to identify the possible routes of infection of BU lesions identified three modes of infection of BU lesions in two health centers in Ghana; two health-care facility related sources, through a HCW and the environment, and a self-infection (Fig. 2). S. aureus was the main bacterial pathogen identified in many of the samples analyzed and these isolates were selected for further studies. The study employed molecular ( $S$. aureus protein A, (spa) typing) and whole genome sequencing (WGS) methods to identify transmission events 
Fig. 2 Spa phylogeny showing clusters and relationships between isolates: Maximum likelihood phylogeny tree based on spa gene typing. The tree was rooted in the midpoint. Numbers in nodes indicate support values in the form of proportions of bootstrap pseudoreplicates. Branches with support values higher than $55 \%$ are collapsed. A-J = the clusters identified. The green colored strains are from Health center A, and the blue ones from Health center B. The yellow coloured circles represent MRSA and the violet circles show isolates from a HCW, patients and equipment in health center B. The red coloured strains in Cluster I were from three lesions of the same patient which had the same spa (t2500) and ST type (ST 3248) [37]



ongoing within the health centers. Phylogenetic analysis of spa types found in $S$. aureus isolates from samples collected from the health center, from HCW's and patients were analyzed. Different clusters were identified and comprised strains isolated in both health centers (clusters A, C, D, H and J), strains found only in Facility 
A (clusters B, G, and I) and strains isolated only in Facility B (clusters E and F) (Fig. 2). Isolates within cluster $\mathrm{F}$ included isolates from samples taken from the hand of a health care worker and from patients dressed consecutively by this worker on the same day, isolates taken on another day from a forceps used to dress patients after it had been used on four different patients consecutively and two isolates from a patient who attended the health facility for treatment at two different time points (weeks 2 and 8) during treatment (Fig. 2). Isolates in cluster I were from three BU lesions of a patient. These isolates had the same spa type (t2500), and sequence type (ST 32489). They had SNP differences of 29 bp, 51 bp and 34 bp between them, and these small numbers of SNPs suggests that they could have been spread from a common source. Similar clusters were also predicted by the WGS analysis [37].

Using a WGS-based-gene-by-gene typing approach, Amissah et al. [12] also identified transmission events between different patients at a health center. Results from this study showed that transmission events could have occurred during overlapping visits of the patients to the health center. Further analysis of the $S$. aureus isolates detected from the wounds showed that they belonged to lineages which have also been reported by other studies from the Ghanaian health-care setting strongly suggesting that these lineages could be associated with transmission within our health centers $[12,40]$.

\section{$7 \quad$ Predisposing Socio-Economic Factors}

Several factors could predispose BU patients to wound infection. Firstly, because of the painlessness of early lesions, most affected people do not report early to the formal health centers for treatment. They resort to home management of the wounds until they have deteriorated and lesions become clinically and microbiologically infected [33]. Secondly, BU is seen in many endemic areas as a spiritual disease. An unhealing wound is thought to be caused by spiritual forces, charms, witches, ancestral spirits or even the gods of the land [41]. These beliefs drive the affected to seek for help from traditional healers and witch doctors as their first point of call and not biomedical health facilities [41-44]. These witch doctors and traditional healers also apply various kinds of concoctions to manage the lesions and these concoctions may not have been prepared under hygienic conditions and may serve as conduits for the introduction of contaminants into the wounds.

Cases are only reported to the biomedical health centers after all efforts have been exhausted by these various approaches and no improvement has been seen. Therefore frequently large wounds are presented which may have been treated over long periods of time with various concoctions usually not prepared under aseptic conditions.

The socio-cultural beliefs and perceptions of the patients also affect their response to treatment even at the formal health centers. Some categories of people such as pregnant women, 'promiscuous people', breastfeeding mothers are considered unqualified to manage wounds in a community. Our research has shown that when patients encounter any of these categories of people in the formal health 
center, they resort to re-dressing their wounds after they have been dressed by these people and thus end up introducing contaminants into their wounds [41].

Economic hardships have also been found to predispose BU patients to wound infection. In Ghana, treatment of the disease is free; however, affected patients have to bear the cost of wound management. This places a huge financial burden on patients and their families, which they are sometimes unable to bear. Thus instead of using fresh bandages anytime the wounds are dressed, patients resort to recycling of old bandages. Some of these bandages are not washed properly after use and analysis of some of the washed bandages by Yeboah-Manu et al. [10] showed that potential pathogens similar to those isolated from the wounds can be isolated from the recycled washed bandages.

\section{$8 \quad$ Prevention of Secondary Infection}

In order to prevent secondary infection, the cycle of events that lead to the contamination of wounds by bacteria must be broken. This will entail dealing with the sources of potential pathogens in order to minimize their spread or transmissibility. In BU wound management, observing aseptic techniques at every stage of wound management is critical to preventing super-infection by other bacteria. Thus education of both HCWs and patients is important and periodic monitoring to ensure compliance with laid down guidelines will also go a long way in reducing the occurrence of secondary infection in BU disease [45]. Decentralized treatment may reduce the risk of nosocomial wound infection compared to in-patient facilities [8]. Guidelines for the prevention and management of wound infection were released in 2010 by the WHO. These guidelines which can be accessed at www.who.int/ gpsc/SSI-outline.pdf?ua=1 provide core principles for the appropriate prevention and management of infected wounds as well as protocols to guide the management of the wound site, tetanus prone wounds and antibiotic prophylaxis and treatment. Separate guidelines for the prevention of surgical site infection (www.who.int/hac/ techguide/tools/guidelines_prevention_and_management_wound_infection.pdf) have also been released by the WHO and these can also be used to strengthen infection prevention and control programmes in the health centers and applied in cases where infected patients require surgical interventions.

\section{$9 \quad$ Wound Care}

The median time to healing in early, limited BU lesions has been found to be 18 weeks [1]. For large lesions, this can be more than 2 years. Therefore, after antibiotic therapy, wound care will form the core of BU wound management until wound closure is achieved and the procedure should be adequate to ensure wound healing by decreasing time to healing, pain and morbidity [46-48].

Basic principles of wound management seek to treat or manage relevant systemic conditions, maintain a moist wound environment [49], protect the wound 
from trauma, promote a clean wound base, prevent infection, and control edema and lymphoedema. Basic wound care depends on the type of wound being managed; however fundamental wound management practices involve cleansing the wound, debriding and applying appropriate dressing materials. The correct type of dressing is essential in maintaining a moist wound environment and decreasing rates of infection [45]. Traditional gauze dressings have been shown to have increased infection rates compared to moisture retaining dressings [47, 49], therefore selection of appropriate dressing is important. Personal observations show that different clinicians use varying dressing materials for BU patients to reduce edema, however none of the dressings have been evaluated in a controlled trial. Other practices that ensure timely wound healing are irrigation with physiological saline solution during cleansing, pain management and working under aseptic conditions. The WHO has two guidelines on wound management that can be applied to BU [50, 51]. However, a study by Velding [45] accessing the wound care practices for BU in Ghana and Benin concluded that they differed from the recommended WHO guidelines [45]. It is important that health centers adhere to the available guidelines on wound care to ensure timely healing of wounds. Though some of the differences in wound management techniques were related to the economic conditions of the health centers, Velding recommends some simple and low cost solutions which can be implemented in the health centers to enhance the standard of wound care [45]. As such, health care workers need to be trained on the appropriate guidelines for wound management and a retraining and monitoring machinery should be put in place to ensure compliance with laid down guidelines.

Many lines of evidence indicate that good wound care practices can decrease the length of hospital stay and also increase the number of wounds healing without surgical intervention. Wound care is expensive and the burden usually falls on the affected patients and their families who are sometimes ill-equipped to handle the financial costs over a long period of time. Good wound care will therefore reduce this burden on the affected individuals by ensuring they do not stay for prolonged periods in the health centers.

\section{References}

1. Nienhuis WA, Stienstra Y, Thompson WA, Awuah PC, Abass KM, Tuah W, Awua-Boateng NY, Ampadu EO, Siegmund V, Schouten JP, Adjei O, Bretzel G, van der Werf TS (2010) Antimicrobial treatment for early, limited Mycobacterium ulcerans infection: a randomised controlled trial. Lancet 375(9715):664-672. https://doi.org/10.1016/S0140-6736(09)61962-0

2. Beissner M, Arens N, Wiedemann F, Piten E, Kobara B, Bauer M, Herbinger KH, Badziklou K, Banla Kere A, Loscher T, Nitschke J, Bretzel G (2015) Treatment outcome of patients with Buruli ulcer disease in Togo. PLoS Negl Trop Dis 9(10):e0004170. https://doi.org/10.1371/ journal.pntd.0004170

3. Chauty A, Ardant MF, Adeye A, Euverte H, Guedenon A, Johnson C, Aubry J, Nuermberger E, Grosset J (2007) Promising clinical efficacy of streptomycin-rifampin combination for treatment of buruli ulcer (Mycobacterium ulcerans disease). Antimicrob Agents Chemother 51(11):4029-4035. https://doi.org/10.1128/AAC.00175-07 
4. Kibadi K, Boelaert M, Fraga AG, Kayinua M, Longatto-Filho A, Minuku JB, Mputu-Yamba JB, Muyembe-Tamfum JJ, Pedrosa J, Roux JJ, Meyers WM, Portaels F (2010) Response to treatment in a prospective cohort of patients with large ulcerated lesions suspected to be Buruli ulcer (Mycobacterium ulcerans disease). PLoS Negl Trop Dis 4(7):e736. https://doi. org/10.1371/journal.pntd.0000736

5. Phillips RO, Sarfo FS, Abass MK, Abotsi J, Wilson T, Forson M, Amoako YA, Thompson W, Asiedu K, Wansbrough-Jones M (2014) Clinical and bacteriological efficacy of rifampinstreptomycin combination for two weeks followed by rifampin and clarithromycin for six weeks for treatment of Mycobacterium ulcerans disease. Antimicrob Agents Chemother 58(2):1161-1166

6. Sarfo FS, Phillips R, Asiedu K, Ampadu E, Bobi N, Adentwe E, Lartey A, Tetteh I, WansbroughJones M (2010) Clinical efficacy of combination of rifampin and streptomycin for treatment of Mycobacterium ulcerans disease. Antimicrob Agents Chemother 54(9):3678-3685. https:// doi.org/10.1128/AAC.00299-10

7. Vincent QB, Ardant MF, Adeye A, Goundote A, Saint-Andre JP, Cottin J, Kempf M, Agossadou D, Johnson C, Abel L, Marsollier L, Chauty A, Alcais A (2014) Clinical epidemiology of laboratory-confirmed Buruli ulcer in Benin: a cohort study. Lancet Glob Health 2(7):e422e430. https://doi.org/10.1016/S2214-109X(14)70223-2

8. Addison NO, Pfau S, Koka E, Aboagye SY, Kpeli G, Pluschke G, Yeboah-Manu D, Junghanss $\mathrm{T}$ (2017) Assessing and managing wounds of Buruli ulcer patients at the primary and secondary health care levels in Ghana. PLoS Negl Trop Dis 11(2):e0005331. https://doi.org/10.1371/ journal.pntd.0005331

9. Andreoli A, Ruf MT, Sopoh GE, Schmid P, Pluschke G (2014) Immunohistochemical monitoring of wound healing in antibiotic treated Buruli ulcer patients. PLoS Negl Trop Dis 8(4):e2809. https://doi.org/10.1371/journal.pntd.0002809

10. Yeboah-Manu D, Kpeli GS, Ruf MT, Asan-Ampah K, Quenin-Fosu K, Owusu-Mireku E, Paintsil A, Lamptey I, Anku B, Kwakye-Maclean C, Newman M, Pluschke G (2013) Secondary bacterial infections of buruli ulcer lesions before and after chemotherapy with streptomycin and rifampicin. PLoS Negl Trop Dis 7(5):e2191. https://doi.org/10.1371/journal.pntd.0002191

11. WHO (2016) Buruli ulcer-diagnosis of Mycobacterium ulcerans disease. WHO, Geneva

12. Amissah NA, Chlebowicz MA, Ablordey A, Sabat AJ, Tetteh CS, Prah I, van der Werf TS, Friedrich AW, van Dijl JM, Rossen JW, Stienstra Y (2015a) Molecular characterization of Staphylococcus aureus isolates transmitted between patients with Buruli ulcer. PLoS Negl Trop Dis 9(9):e0004049. https://doi.org/10.1371/journal.pntd.0004049

13. Anyim MC, Meka AO, Chukwu JN, Nwafor CC, Oshi DC, Madichie NO, Ekeke N, Alphonsus C, Mbah O, Nwaekpe C, Njoku M, Fakiyesi D, Ulodiaku V, Ejiofor I, Bisiriyu AH, Ukwaja KN (2016) Secondary bacterial isolates from previously untreated Buruli ulcer lesions and their antibiotic susceptibility patterns in Southern Nigeria. Rev Soc Bras Med Trop 49(6):746751. https://doi.org/10.1590/0037-8682-0404-2016

14. Barogui YT, Klis S, Bankole HS, Sopoh GE, Mamo S, Baba-Moussa L, Manson WL, Johnson RC, van der Werf TS, Stienstra Y (2013) Towards rational use of antibiotics for suspected secondary infections in Buruli ulcer patients. PLoS Negl Trop Dis 7(1):e2010. https://doi. org/10.1371/journal.pntd.0002010

15. Phanzu DM, Bafende EA, Dunda BK, Imposo DB, Kibadi AK, Nsiangana SZ, Singa JN, Meyers WM, Suykerbuyk P, Portaels F (2006) Mycobacterium ulcerans disease (Buruli ulcer) in a rural hospital in Bas-Congo, Democratic Republic of Congo, 2002-2004. Am J Trop Med Hyg 75(2):311-314

16. van der Werf TS, van der Graaf WT, Tappero JW, Asiedu K (1999) Mycobacterium ulcerans infection. Lancet 354(9183):1013-1018. https://doi.org/10.1016/S0140-6736(99)01156-3

17. Katz L, Donadio S (1993) Polyketide synthesis: prospects for hybrid antibiotics. Annu Rev Microbiol 47:875-912. https://doi.org/10.1146/annurev.mi.47.100193.004303

18. Scherr N, Gersbach P, Dangy JP, Bomio C, Li J, Altmann KH, Pluschke G (2013) Structureactivity relationship studies on the macrolide exotoxin mycolactone of Mycobacterium ulcerans. PLoS Negl Trop Dis 7(3):e2143. https://doi.org/10.1371/journal.pntd.0002143 
19. Bowler PG, Duerden BI, Armstrong DG (2001) Wound microbiology and associated approaches to wound management. Clin Microbiol Rev 14(2):244-269. https://doi. org/10.1128/CMR.14.2.244-269.2001

20. Guo S, Dipietro LA (2010) Factors affecting wound healing. J Dent Res 89(3):219-229. https://doi.org/10.1177/0022034509359125

21. Percival SL, Dowd SE (2010) The microbiology of wounds. CFC Press, Boca Raton, FL

22. Davis SC, Ricotti C, Cazzaniga A, Welsh E, Eaglstein WH, Mertz PM (2008) Microscopic and physiologic evidence for biofilm-associated wound colonization in vivo. Wound Repair Regen 16(1):23-29. https://doi.org/10.1111/j.1524-475X.2007.00303.x

23. Percival SL, McCarty SM, Lipsky B (2015) Biofilms and wounds: an overview of the evidence. Adv Wound Care (New Rochelle) 4(7):373-381. https://doi.org/10.1089/wound.2014.0557

24. Tarnuzzer RW, Schultz GS (1996) Biochemical analysis of acute and chronic wound environments. Wound Repair Regen 4(3):321-325. https://doi.org/10.1046/j.1524-475X.1996.40307.x

25. Bendy RH Jr, Nuccio PA, Wolfe E, Collins B, Tamburro C, Glass W, Martin CM (1964) Relationship of quantitative wound bacterial counts to healing of decubiti: effect of topical gentamicin. Antimicrob Agents Chemother (Bethesda) 10:147-155

26. Majewski W, Cybulski Z, Napierala M, Pukacki F, Staniszewski R, Pietkiewicz K, Zapalski S (1995) The value of quantitative bacteriological investigations in the monitoring of treatment of ischaemic ulcerations of lower legs. Int Angiol 14(4):381-384

27. Daltrey DC, Rhodes B, Chattwood JG (1981) Investigation into the microbial flora of healing and non-healing decubitus ulcers. J Clin Pathol 34(7):701-705

28. Edwards R, Harding KG (2004) Bacteria and wound healing. Curr Opin Infect Dis 17(2):9196. https://doi.org/10.1097/00001432-200404000-00004

29. Krizek TJ, Robson MC, Kho E (1967) Bacterial growth and skin graft survival. Surg Forum 18:518-519

30. Lookingbill DP, Miller SH, Knowles RC (1978) Bacteriology of chronic leg ulcers. Arch Dermatol 114(12):1765-1768

31. Pruitt BA Jr, McManus AT, Kim SH, Goodwin CW (1998) Burn wound infections: current status. World J Surg 22(2):135-145

32. Robson MC, Heggers JP (1969) Bacterial quantification of open wounds. Mil Med 134(1):19-24

33. Kpeli G, Owusu-Mireku E, Hauser J, Pluschke G, Yeboah-Manu D (2017b) Longitudinal assessment of the bacterial burden of buruli ulcer wounds during treatment. BBRJ 1(1):65-70. https://doi.org/10.4103/bbrj.bbrj_37_17

34. Gardner SE, Hillis SL, Frantz RA (2009) Clinical signs of infection in diabetic foot ulcers with high microbial load. Biol Res Nurs 11(2):119-128. https://doi.org/10.1177/1099800408326169

35. Gardner SE, Frantz RA, Doebbeling BN (2001) The validity of the clinical signs and symptoms used to identify localized chronic wound infection. Wound Repair Regen 9(3):178-186

36. Schraibman IG (1990) The significance of beta-haemolytic streptococci in chronic leg ulcers. Ann R Coll Surg Engl 72(2):123-124

37. Kpeli G, Darko Otchere I, Lamelas A, Buultjens AL, Bulach D, Baines SL, Seemann T, Giulieri S, Nakobu Z, Aboagye SY, Owusu-Mireku E, Pluschke G, Stinear TP, Yeboah-Manu D (2016) Possible healthcare-associated transmission as a cause of secondary infection and population structure of Staphylococcus aureus isolates from two wound treatment centres in Ghana. New Microbes New Infect 13:92-101. https://doi.org/10.1016/j.nmni.2016.07.001

38. Amissah NA, Glasner C, Ablordey A, Tetteh CS, Kotey NK, Prah I, van der Werf TS, Rossen JW, van Dijl JM, Stienstra Y (2015b) Genetic diversity of Staphylococcus aureus in Buruli ulcer. PLoS Negl Trop Dis 9(2):e0003421. https://doi.org/10.1371/journal.pntd.0003421

39. Kpeli G, Buultjens AH, Giulieri S, Owusu-Mireku E, Aboagye SY, Baines SL, Seemann T, Bulach D, Goncalves da Silva A, Monk IR, Howden BP, Pluschke G, Yeboah-Manu D, Stinear T (2017a) Genomic analysis of ST88 community-acquired methicillin resistant Staphylococcus aureus in Ghana. PeerJ 5:e3047. https://doi.org/10.7717/peerj.3047

40. Egyir B, Guardabassi L, Sorum M, Nielsen SS, Kolekang A, Frimpong E, Addo KK, Newman MJ, Larsen AR (2014) Molecular epidemiology and antimicrobial susceptibility of clinical 
Staphylococcus aureus from healthcare institutions in Ghana. PLoS One 9(2):e89716. https:// doi.org/10.1371/journal.pone.0089716

41. Koka E, Yeboah-Manu D, Okyere D, Adongo PB, Ahorlu CK (2016) Cultural understanding of wounds, Buruli ulcers and their management at the Obom sub-district of the Ga south municipality of the Greater Accra region of Ghana. PLoS Negl Trop Dis 10(7):e0004825. https://doi. org/10.1371/journal.pntd.0004825

42. Asiedu K, Etuaful S (1998) Socioeconomic implications of Buruli ulcer in Ghana: a three-year review. Am J Trop Med Hyg 59(6):1015-1022

43. Aujoulat I, Johnson C, Zinsou C, Guedenon A, Portaels F (2003) Psychosocial aspects of health seeking behaviours of patients with Buruli ulcer in southern Benin. Tropical Med Int Health 8(8):750-759

44. Renzaho AM, Woods PV, Ackumey MM, Harvey SK, Kotin J (2007) Community-based study on knowledge, attitude and practice on the mode of transmission, prevention and treatment of the Buruli ulcer in Ga West District, Ghana. Tropical Med Int Health 12(3):445-458. https:// doi.org/10.1111/j.1365-3156.2006.01795.x

45. Velding K, Klis SA, Abass KM, Tuah W, Stienstra Y, van der Werf T (2014) Wound care in Buruli ulcer disease in Ghana and Benin. Am J Trop Med Hyg 91(2):313-318. https://doi. org/10.4269/ajtmh.13-0255

46. Beldon P (2004) Comparison of four different dressings on donor site wounds. Br J Nurs $13(6$ Suppl):S38-S45. https://doi.org/10.12968/bjon.2004.13.Sup1.12541

47. Brolmann FE, Eskes AM, Goslings JC, Niessen FB, de Bree R, Vahl AC, Pierik EG, Vermeulen H, Ubbink DT (2013) Randomized clinical trial of donor-site wound dressings after split-skin grafting. Br J Surg 100(5):619-627. https://doi.org/10.1002/bjs.9045

48. Chang KW, Alsagoff S, Ong KT, Sim PH (1998) Pressure ulcers--randomised controlled trial comparing hydrocolloid and saline gauze dressings. Med J Malaysia 53(4):428-431

49. Singh A, Halder S, Menon GR, Chumber S, Misra MC, Sharma LK, Srivastava A (2004) Metaanalysis of randomized controlled trials on hydrocolloid occlusive dressing versus conventional gauze dressing in the healing of chronic wounds. Asian J Surg 27(4):326-332. https:// doi.org/10.1016/S1015-9584(09)60061-0

50. Lehman L, Simonet V, Saunderson P, Agbenorku P (2006) Buruli ulcer: prevention of disability (POD). World Health Organization, Geneva

51. Macdonald JM, Geyer MJ (2010) Wound and lymphoedema management. World Health Organization, Geneva

Open Access This chapter is licensed under the terms of the Creative Commons Attribution 4.0 International License (http://creativecommons.org/licenses/by/4.0/), which permits use, sharing, adaptation, distribution and reproduction in any medium or format, as long as you give appropriate credit to the original author(s) and the source, provide a link to the Creative Commons license and indicate if changes were made.

The images or other third party material in this chapter are included in the chapter's Creative Commons license, unless indicated otherwise in a credit line to the material. If material is not included in the chapter's Creative Commons license and your intended use is not permitted by statutory regulation or exceeds the permitted use, you will need to obtain permission directly from the copyright holder.

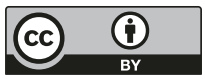

